Original Research

\title{
Effectiveness of Cognitive Behavioral Therapy to Reduce Depression, Anxiety and Stress among Hospitalized Patients with Congestive Heart Failure in Central Java
}

\author{
Dian Hudiyawati and Ajie Maulana Prakoso \\ Faculty of Nursing, Universitas Muhammadiyah Surakarta, Indonesia
}

\begin{abstract}
Introduction: Psychological problems in patients with heart failure are the result of a combination of the influence of behavior and interactions with physiological responses, which if not handled properly will contribute to worsening clinical symptoms and have a higher risk of rehospitalization. The objective of the study was to evaluate the effects of cognitive behavior therapy (CBT) on psychological symptoms among CHF patients.
\end{abstract}

Methods: This was a quasi-experimental, pretest-posttest control study that applying a CBT to overcome depression, anxiety, and stress. Thirty eligible respondents were recruited and were randomly divided into a case group and waiting list group. Psychological symptoms of respondents were measured using Depression, Anxiety and Stress Scale - 21 questionnaires (DASS-21). Chi-square was used to compare demographic data between groups and T-test analysis was used to describe changes in mean scores between and within groups. Both groups had similar characteristics and psychological symptoms level at baseline.

Results: The mean score of depression, anxiety and stress showed a significant difference within the group after the intervention $(\mathrm{p}<0.05)$.

Conclusion: A recent study found that CBT was effective to reduce psychological symptoms among CHF patients. Based on the study results it can be highlighted that it is important for nurses to provide brief CBT to hospitalized patients in an effort to reduce short term psychological symptoms.

\section{ARTICLE HISTORY}

Received: Dec 26, 2019

Accepted: Dec 31, 2019

\section{KEYWORDS}

heart failure; psychological problems; CBT; depression; anxiety; stress

\section{CONTACT}

Dian Hudiyawati

$\triangle$ dian.hudiyawati@ums.ac.id

$\supseteqq$ Faculty of Nursing, Universitas

Muhammadiyah Surakarta, Indonesia

Cite this as: Hudiyawati, D\& Prakoso, A.J. (2019). Effectiveness of Cognitive Behavioral Therapy to Reduce Depression, Anxiety and Stress among Hospitalized Patients with Congestive Heart Failure in Central Java. Jurnal Ners, 14(3si), 367-373. doi:http://dx.doi.org/10.20473/jn.v14i3(si).17215

\section{INTRODUCTION}

Congestive heart failure is a clinical syndrome in which the heart is inadequate in pumping blood to meet the body's needs (Ponikowski et al., 2014). Heart failure is a major cause of hospitalization with high mortality and rehospitalization rates, which increases the high economic burden on the nation's health system due to the high cost of care (Parissis, Fountoulaki, Paraskevaidis, \& Kremastinos, 2005). In developed countries, it is estimated that one in five people will experience heart failure (Lloyd-Jones et al., 2002). About 26 million adults worldwide suffer from heart failure, so it should be made as a global health priority. In the US, around 5.8 million people suffered from heart failure in 2012, and it is predicted will increase to 8.5 million by 2030 (Ponikowski et al.,
2014). Other contributing factors in increasing the prevalence of heart failure are improving the survival rates of patients with heart attacks or other cardiovascular diseases, due to improvement in diagnosis and medical management. In addition, in some countries the majority of the population are elderly people who are expected to increase the number of heart failure patients (Hobbs, Korewicki, Cleland, Eastaugh, \& Freemantle, 2005).

In economically developing countries, such as Indonesia, the number of patients with heart failure has also risen. This incidence is a result of transformation culture related to western-type lifestyles and its related diseases, for example, conditions such as diabetes increase the risk of heart failure (Sato, 2015). In recent years, heart failure patients were hospitalized with complications from 
other diseases, resulting in a longer length of stay in a hospital. Moreover, patients will experience rehospitalization repeatedly because of their condition (Sasayama, 2008). This situation represents that heart failure is a global healthcare burden in Indonesia.

Heart failure greatly affects the physiological condition of the patient, such as anxiety and depression. The association between heart failure and depression symptoms has been revealed in several studies (Sohani \& Samaan, 2012). Based on the previous studies around $9 \%$ to $60 \%$ of heart failure patients experience depression (Vaccarino, Kasl, Abramson, \& Krumholz, 2001). Heart failure patients who experience psychological symptoms have a higher risk of hospitalization and death compared to those who are free from depression (Jeyanantham, Kotecha, Thanki, Dekker, \& Lane, 2017; Parissis et al., 2005). The exact mechanism that psychological problems cause worse results in patients with heart failure is not clear but are estimated by a combination of the influence of behavior and interactions with physiological responses (O' Connor, 2018). Moreover, the influence behavior of psychological issues can reduce the possibility of treatment compliance and lifestyle behavior modification, which may subsequently contribute to poor prognosis (Pihl, Jacobsson, Fridlund, Strömberg, \& Mårtensson, 2005). Lately, depression and anxiety in patients with chronic diseases are targeted by many psychoeducation programs. This statement is supported by research from Dusseldorp et al. who conducted a meta-analysis of psychoeducation programs for coronary heart disease patients. The results of the study found a reduction in mortality and recurrence of myocardial infarction, respectively by $34 \%$ and $29 \%$, and contributed to changes in better self-care management (Dusseldorp, Van Elderen, Maes, Meulman, \& Kraaij, 1999).

Cognitive Behavioral Therapy (CBT) is presently suggested to overcome anxiety and depression by the National Institute for Health and Care Excellence (NICE) in the United Kingdom (NICE, 2014). Cognitive behavioral approaches are based on the concept that psychological problems such as depression, anxiety, and stress are often exacerbated by overthinking. CBT practitioners, then, will help the patients identify their mindsets and change their traits using evidence and logic. CBT seems to be effectual for rectifying psychological health. The objective of CBT training is to assist patients to identify maladaptive behavior and irrelevant pattern of thought through directed discussion and organized behavior. Based on the description above, it might conclude that a CBT program could help heart failure patients in reducing depression, anxiety, and stress by teaching coping strategies that focus on problems. Therefore, the objective of the present study was to investigate the short session of cognitive behavioral therapy in reducing depression, anxiety, and stress among hospitalized patients with congestive heart failure.

\section{MATERIALS AND METHODS}

A quasi-experimental study using simple randomization was allocated comparing administered brief CBT interventions with the usual care for treating psychological problems. Thirty (30) eligible respondents from a cardiovascular unit in Moewardi Hospital, Central Java were conducted in a recent study. The inclusion criteria included heart failure patients who admitted with aged $\geq 18$ years, had an NYHA classification I-IV, hemodynamically

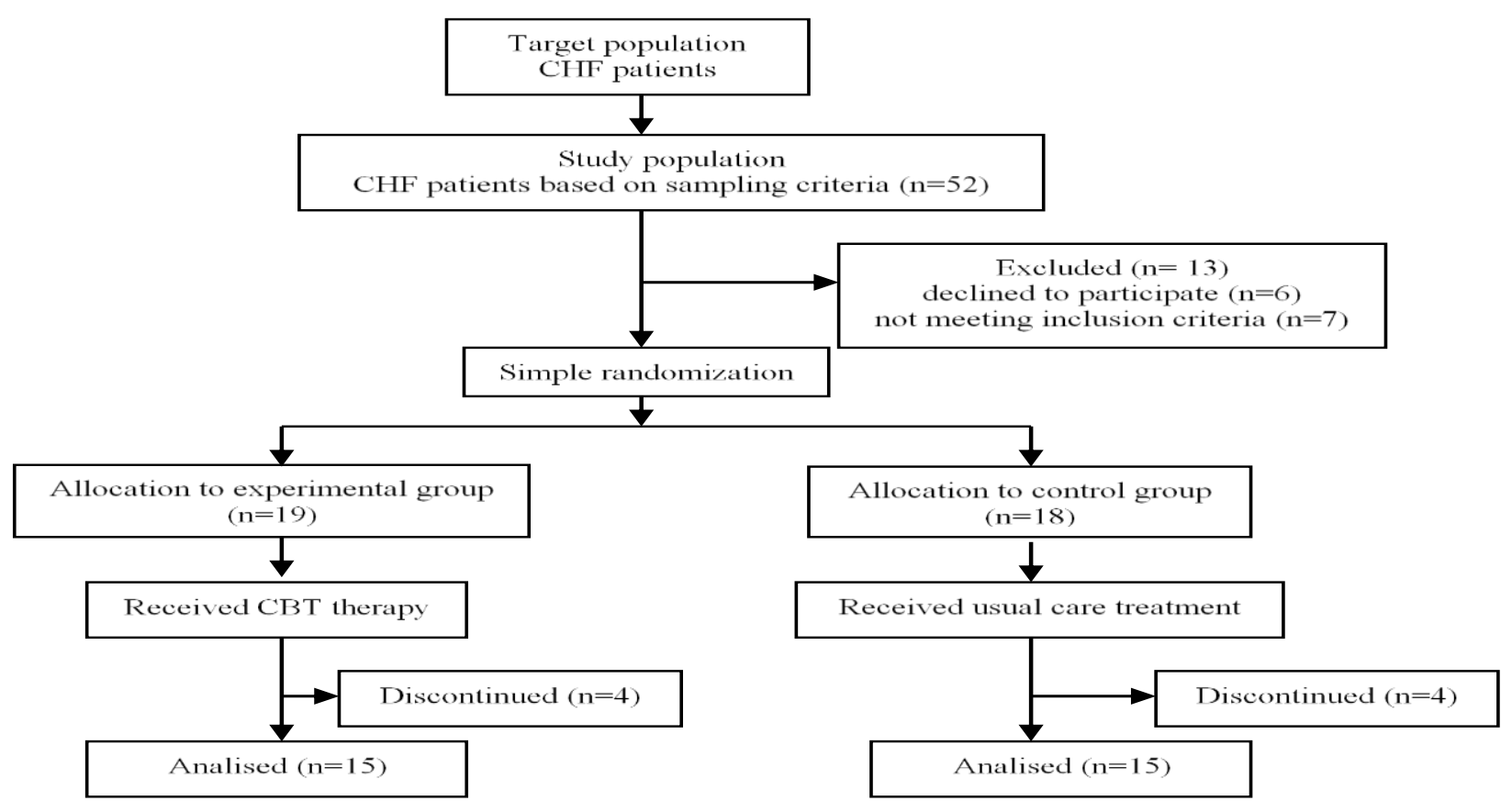

Figure 1. Research design as per the CONSORT guidelines, 2010 


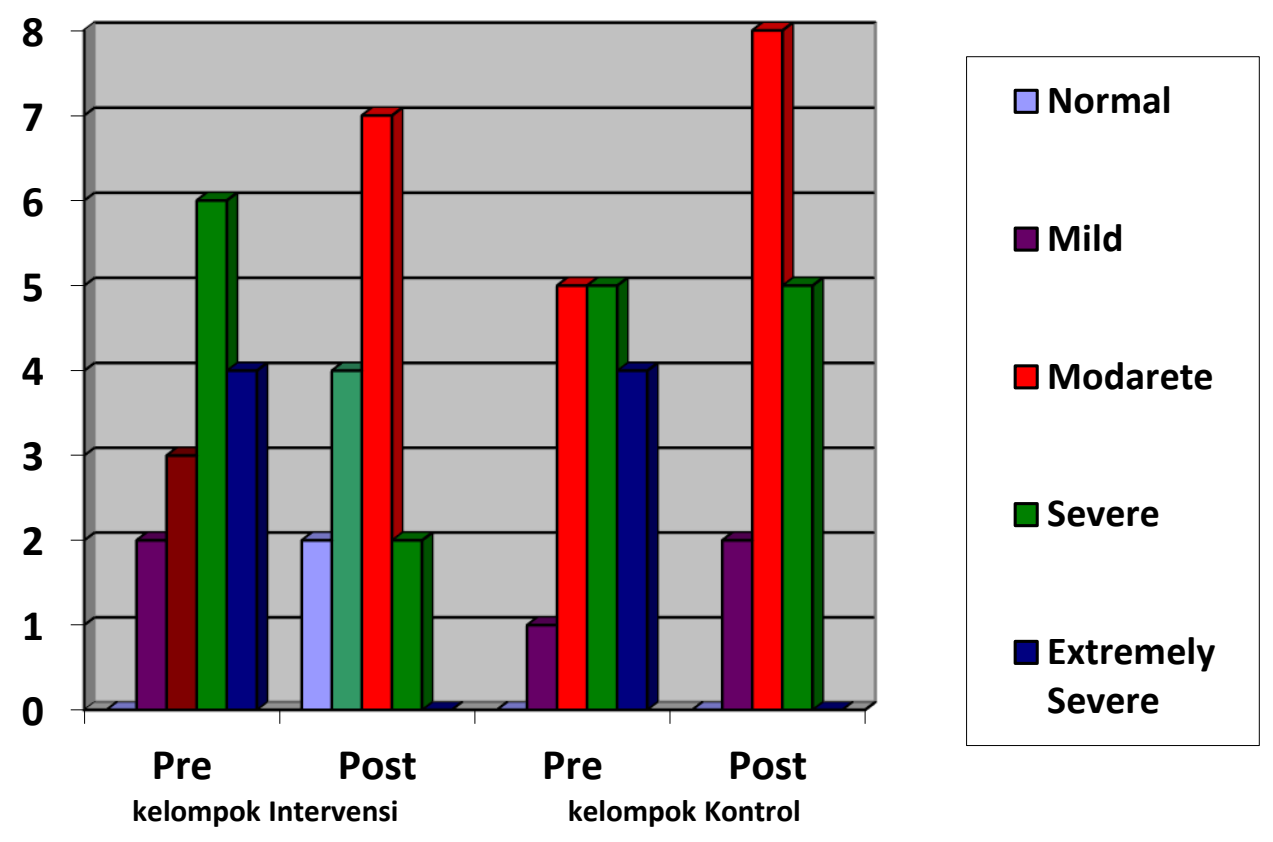

Figure 2. Pre-Post Anxiety Level Data Histogram Between the Control Group and Intervention Group

stable and concurred to follow the study procedure. Exclusion criteria included patients with antidepressant medication, the experience of psychotic illness or mental disorder.

The estimated sample size of 30 respondents was based on a formula of two independent mean groups and parameters used were from Essa, et al (Essa, Ismail, \& Hassan, 2017). Fifteen (15) respondents were conducted into the study and wait-list control groups. Eligible respondents in the study groups received Cognitive Behavioral Therapy (CBT) training from CBT practitioners who were formally trained in CBT. The respondents were given instructions on the steps of the CBT session while those in the wait-list control groups only received the intervention after completion of the study. This research design scheme is based on CONSORT 2010 and presented in (Figure 1) (Schulz, Altman, \& Moher, 2011).

The CBT group was individual training consisting of five sessions of CBT, 20-30 minutes during each session over 3 days. The session commenced with exploring and discussion problems faced by patients. Content included formulating problems as the focus of therapy goal (session 1), activity planning (session 2), structured problem solving (session 3), strategies to improve motivation (session 4), evaluate new strategies (session 5). Finally, respondents in the intervention and control groups were re-evaluated on their depression, anxiety and stress level using the same set of a questionnaire of DASS 21.

\section{CBT Procedure}

First day. First Session (8 AM), asking patient problems (what, when, why and how) and exploring problems to be formulated (with patients) to be agreed upon as the focus of therapy. Second Session
(1 PM), examine and formulate behavioral consequences or somatic reactions (perhaps the main problem of the patient) so that patients need help or treatment $(\mathrm{C})$, check or explore events that might be the originator or cause of the patient's problems (A), recognizing a patient's negative cognitive status (B) in the form of an irrational belief system, reaching the belief or belief relationship with the consequences of that belief. The second day. Third Session (8 AM), an irrational or negative examination of beliefs and prepare rational or positive beliefs. Fourth Session (1 $\mathrm{PM}$ ), encourage learning to practice new beliefs.The third day. Fifth Session (8 AM), evaluating new beliefs.

\section{The instrument for outcome measure}

All respondents from CBT group and usual care groups were assessed for their depression, anxiety and stress level using a set of pre-tested, selfadministered and validated questionnaires which involve Depression, Anxiety, Stress Scale 21 (DASS 21 ) in the Indonesian language as a baseline measure prior to the implementation of the intervention and post-intervention. DASS-21 consists of total of 21 items comprised of 3 domains which measuring depression, anxiety, and stress. Each domain has 7 items that reflect symptoms related to those 3 psychological measures. Patients are asked to score each item on a scale of 0 (not valid for me at all) to 3 (applied to me very much). The total score is calculated by summing the scores on the per (sub) scale items then multiplied by 2 . The sum of the total DASS scale ranges from $0-120$, and the scores for each subscale range from $0-42$. The cut-off score 60 is used for the score total DASS, while the cut-off 21 is utilized for each sub-scale items (Tran, Tran, \& Fisher, 
Table 1. Depression anxiety and stress 21 sub-scale severity ratings suggested for Australian

\begin{tabular}{|c|c|c|c|}
\hline Severity & DASS21-D & DASS21-A & DASS21-S \\
\hline Normal & $0-9$ & $0-7$ & $0-14$ \\
\hline Mild & $10-13$ & $8-9$ & $15-18$ \\
\hline Moderate & $14-20$ & $10-14$ & $19-25$ \\
\hline Severe & $21-27$ & $15-19$ & $26-33$ \\
\hline Extremely severe & $28+$ & $20+$ & $34+$ \\
\hline
\end{tabular}

Table 2. Baseline comparison of socio-demographic characteristics between intervention and control groups

\begin{tabular}{|c|c|c|c|c|c|}
\hline \multirow[t]{2}{*}{ Variable } & \multicolumn{2}{|c|}{ Intervention group } & \multicolumn{2}{|c|}{ Control group } & \multirow[t]{2}{*}{$\mathrm{P}$ value } \\
\hline & $(\mathrm{N}=15)$ & $\%$ & $(\mathrm{~N}=15)$ & $\%$ & \\
\hline \multicolumn{6}{|l|}{ Age (years old) } \\
\hline a. $18-30$ & 3 & 20.00 & 2 & 13.33 & 0.882 \\
\hline b. $31-40$ & 3 & 20.00 & 2 & 13.33 & \\
\hline c. $\quad 41-50$ & 4 & 26.67 & 5 & 33.33 & \\
\hline d. $\quad 51-60$ & 5 & 33.33 & 6 & 40.00 & \\
\hline \multicolumn{6}{|l|}{ Gender } \\
\hline a. Men & 5 & 33.33 & 6 & 40.00 & 0.786 \\
\hline b. Women & 10 & 66.67 & 9 & 60.00 & \\
\hline \multicolumn{6}{|l|}{ Education level } \\
\hline a. No School & 0 & 0.00 & 1 & 6.67 & 0.324 \\
\hline b. Grade School & 6 & 40.00 & 4 & 26.67 & \\
\hline c. Junior High School & 4 & 26.27 & 7 & 46.67 & \\
\hline d. High School & 5 & 33.33 & 3 & 20.00 & \\
\hline \multicolumn{6}{|l|}{ NYHA Level } \\
\hline a. I & 3 & 20.00 & 5 & 33.33 & 0.801 \\
\hline b. II & 4 & 26.67 & 3 & 20.00 & \\
\hline c. III & 8 & 53.33 & 7 & 46.67 & \\
\hline
\end{tabular}

Table 3. Total score (mean) of the intervention group and the control group

\begin{tabular}{|c|c|c|c|}
\hline \multirow[t]{2}{*}{ Item } & intervention group $(\mathrm{n}=30)$ & control group $(n=30)$ & \multirow[t]{2}{*}{ P value* } \\
\hline & Mean \pm SD & Mean \pm SD & \\
\hline \multicolumn{4}{|c|}{ Depression } \\
\hline Pre-test & $26.13 \pm 9.870$ & $28.27 \pm 10.306$ & 0.567 \\
\hline Post-test & $14.27 \pm 7.005$ & $22.93 \pm 8.481$ & 0.005 \\
\hline \multicolumn{4}{|l|}{ Anxiety } \\
\hline Pre-test & $25.20 \pm 11.608$ & $26.80 \pm 9.792$ & 0.686 \\
\hline Post-test & $15.20 \pm 8.029$ & $21.47 \pm 8.331$ & 0.045 \\
\hline \multicolumn{4}{|l|}{ Stress } \\
\hline Pre-test & $26.80 \pm 9.792$ & $27.07 \pm 10.552$ & 0.943 \\
\hline Post-test & $15.07 \pm 8.713$ & $22.13 \pm 9.456$ & 0.042 \\
\hline
\end{tabular}

*Significant level $\mathrm{p}<0.05$

2013). The DASS sub-scale severity ratings suggested for this study are shown in Table 1. DASS-21 has good validity and internal consistency in Indonesian studies and Cronbach's alpha value from DASS-21 in this study is 0.914 .

\section{Ethics consideration}

The study obtained ethical approval from the hospital ethics committee and all respondents provided informed consent and signed it prior to the study. The respondents from the wait-list group were given an option to undergo the CBT training after completion of the study. The respondents were also ensured that confidentiality was maintained throughout the study period.

\section{Statistical Analysis}

The data was analyzed using a computer program. Frequency, percentage, mean and standard deviation were used in the descriptive analysis. Chi-square test was used to compare the demographic variables between intervention and control groups. Independent t-test was used to compare the mean depression, anxiety and stress scores between groups, while paired t-test was used to evaluate the short session CBT in reducing depression, stress, and anxiety after an intervention. The significance level was set at $0.05(\mathrm{P}<0.05)$.

\section{RESULTS}

Respondents' demographic characteristics are presented in table 1 . There were no significant differences found on any of the personal characteristic of the respondents between the short session CBT group ( $\mathrm{n}=15)$ or the usual care group ( $\mathrm{n}$ $=15)(p>0.05)$. A total of 30 eligible respondents were included in the recent study. The majority of the final sample was male (67\%) and in the mean age 63 years (age group 52-60 years old; 33\%).

Table 2 shows the comparison of mean scores of depression, anxiety and stress between intervention 
and control groups at baseline (pre-test) and after an intervention (post-test). There was no significant difference in mean scores of depression $(p=0.567)$, anxiety $(p=0.686)$ and stress $(p=0.946)$ between intervention and control groups at baseline. Meanwhile, the mean scores of depression $(p=0.005)$, anxiety $(p=0.045)$ and stress $(p=0.042)$ between both groups significantly different after intervention.

Table 2 shows the comparison of mean scores of depression, anxiety and stress between intervention and control groups at baseline (pre-test) and after intervention (post-test). There was no significant difference in mean scores of depression $(p=0.691)$, anxiety $(p=0.743)$ and stress $(p=0.546)$ between intervention and control groups at baseline. Meanwhile, the mean scores of depression $(p=0.001)$, anxiety $(p=0.001)$ and stress $(p=0.001)$ between both groups were significantly different after intervention.

\section{DISCUSSION}

The present study found that half of the respondents were male. This result is in line with the study from Kao, et al. who stated that the number of CHF patients is higher in males (54.4\%) than females (45.6\%) (Kao et al., 2014), which the result was repeated in the study conducted by Gottlieb, et al that states $\mathrm{CHF}$ is more prevalent in male than female (Gottlieb SS, Khatta M, Friedmann E, Einbinder L, Katzen S, Baker B, 2004). The Framingham study also states that the prevalence increases notably with advancing age, rising to $6.6 \%$ and $7.9 \%$ in male and female, respectively (Lloyd-Jones et al., 2002).

The majority of the CHF patients from this study were in the age group of 51-60 years old (37\%). This finding concurs with the previous study from Bui, et al. which argued that the growing prevalence of $\mathrm{CHF}$ might reflect an aging population (Gaviţa, David, Bujoreanu, Tiba, \& Ionuţiu, 2012). In other words, the older person will have a higher risk of heart failure.

\section{Depression, anxiety and stress among congestive heart failure patients}

High levels of depression, anxiety, and stress were reported in the recent study. This result is similar to the study conducted by Castillon, at al. found that almost $50 \%$ of CHF patients have suffered psychological problems especially depression (Guallar-Castillón et al., 2006). This result also supported by Pihl, et al., it was revealed that around $60 \%$ of CHF patients experienced depression symptoms (Lefteriotis, 2013). Depression, anxiety, and stress symptoms were found to be related by the uncertainty experienced by patients in regards to their disease progression and long-term care (Jeyanantham et al., 2017).

\section{Effectiveness of CBT in depression, anxiety, and stress}

The average depression score in the CBT group was statistically significantly decreased compared to the usual care group score after the CBT program. This finding was supported by a previous study that examined 193 implantable cardioverter defibrillator (ICD) patients, it was found that 96 respondents in the CBT group experienced greater improvement of depression symptoms. The instrument used in this study was the Hospital Anxiety and Depression Scale. Whereas, the current study used a depression subscale from DASS-21. It is seen that whatever questionnaire is used, cognitive behavioral therapy is consistently found to reduce depression scores (Sheu, Irvin, Lin, \& Mar, 2003).

The mean anxiety score in the experimental group was also statistically lower than usual cardiac care after the application of cognitive behavioral therapy. This result is in line with the study result conducted by Valsaraj, et al., the finding was found that CBT was significant for reducing anxiety and depression in the hemodialysis patients (Valsaraj, Bhat, \& Latha, 2016). Both studies used the DASS-21 anxiety subscale, but the follow-up of the CBT program in the previous study was longer. However, in the short sessions measurements between the two studies also showed a significant reduction in the mean anxiety score.

The study also found that the average stress score was significantly lower in the intervention group than in the control group after the intervention. this finding is supported by a study from Gavita et al., who examined 97 Romanian Foster Parents with the results that the CBT group significantly reduced parental emotional distress (Gavița et al., 2012). Previous studies used "the profile of emotional distress", meanwhile in the recent study used the stress subscale from DASS-21. Apart from the different questionnaires in both of studies, the mean stress score decreased significantly after the cognitive behavioral therapy program.

In all previous research and current research, the contents of cognitive behavioral therapy sessions, number of sessions, and administration and session procedures differed. In addition, this study differs in a number of samples, sample size, presence or absence of a control group, number of variables, data collection methods, and methods of data analysis. However, if CBT is carried out appropriately and according to the concept and the principle will be able to help patients in dealing with stress, anxiety, and depression. However, the results of the present study were limited by the small sample sizes and lack of long term follow-up. The true random allocation of the respondents is also limited, therefore may contribute to the selection bias. The blinding process is also limited as the process of masking the intervention was not possible. In view of these limitations, future research is suggested to include multiple study locations and the study design would take into account the true randomization and blinding process. Larger and more robust RCTs are needed to ascertain the long-term benefits and costeffectiveness of a CBT intervention for depression, anxiety, and stress in congestive heart failure patients.

\section{CONCLUSION}

http://e-journal.unair.ac.id/JNERS | 371 
In Conclusion, brief CBT is identified to be more effective than usual care at reducing depression, anxiety and stress symptoms in congestive heart failure patients. Future studies can formulate CBT programs into a simple package that can be applied by a health care providers in a hospital.

\section{REFERENCES}

Ponikowski P, Anker SD, AlHabib KF, Cowie MR, Force TL, Hu S, et al. 2014 Heart failure: preventing disease and death worldwide ESC Heart Failure. Available from: http://dx.doi.org/10.1002/2055-5822.12005

Parissis JT, Fountoulaki K, Paraskevaidis I, Kremastinos D 2005 Depression in chronic heart failure: novel pathophysiological mechanisms and therapeutic approaches. Expert opinion on investigational drugs Informa Healthcare 14 567-77. Available from:

http://dx.doi.org/10.1517/13543784.14.5.5 $\underline{67}$

Lloyd-Jones DM, Larson MG, Leip EP, Beiser A, D'Agostino RB, Kannel WB, et al. 2002 Lifetime risk for developing congestive heart failure Circulation 106 3068-72. Available from:

http://dx.doi.org/10.1161/01.cir.000003910 $\underline{5.49749 .6 \mathrm{f}}$

Hobbs FDR, Korewicki J, Cleland JGF, Eastaugh J, Freemantle N 2005 The diagnosis of heart failure in European primary care: the improvement programme survey of perception and practice European Journal of Heart Failure 7 768-79. Available from: http://dx.doi.org/10.1016/j.ejheart.2005.01. $\underline{018}$

Sato $\mathrm{N} \frac{018}{2015}$ Epidemiology of heart failure in Asia. Heart Failure Clinics 11 573-9. Available from: http://dx.doi.org/10.1016/j.hfc.2015.07.009

Sasayama S 2008 Heart disease in Asia Circulation 118 2669-71. Available from: https://doi.org/10.1161/CIRCULATIONAHA. 108.837054

Sohani ZN, Samaan Z 2012 Does depression impact cognitive impairment in patients with heart failure? Cardiology Research and Practice 1-9. Available from: http://dx.doi.org/10.1155/2012/524325

Vaccarino V, Kasl SV, Abramson J, Krumholz HM 2001 Depressive symptoms and risk of functional decline and death in patients with heart failure Journal of the American College of Cardiology 38 199-205. Available from: http://dx.doi.org/10.1016/s07351097(01)01334-1

Jeyanantham K, Kotecha D, Thanki D, Dekker R, Lane DA 2017 Effects of cognitive behavioral therapy for depression in heart failure patients: a systematic review and metaanalysis Heart Failure Reviews 22 731-41.
Available

from:

http://dx.doi.org/10.1007/s10741-0179640-5

O'Connor CM 2018 Depression in Heart Failure JACC: Heart Failure 6 885-6. Available from: http://dx.doi.org/10.1016/i.jchf.2018.08.004

Pihl E, Jacobsson A, Fridlund B, Strömberg A, Måtensson J 2005 Depression and healthrelated quality of life in elderly patients suffering from heart failure and their spouses: a comparative study European Journal of Heart Failure 7 583-9. Available from: http://dx.doi.org/10.1016/j.ejheart.2004.07. $\underline{016}$

Dusseldorp E, van Elderen T, Maes S, Meulman J, Kraaij V 1999 A meta-analysis of psychoeducational programs for coronary heart disease patients Health Psychology 18 506-19. Available from: http://dx.doi.org/10.1037/0278$\underline{6133.18 .5 .506}$

NICE 2014 Chronic kidney disease in adult: Assessment and Management. Available from: nice.org.uk/guidance/cg182

Essa RM, Ismail NIAA, Hassan NI 2017 Effect of progressive muscle relaxation technique on stress, anxiety, and depression after hysterectomy Journal of Nursing Education and Practice 7 77. Available from: http://dx.doi.org/10.5430/jnep.v7n7p77

Schulz KF, Altman DG, Moher D 2010 CONSORT 2010 Statement: updated guidelines for reporting parallel group randomised trials Trials $\mathbf{1 1}$. Available

from: http://dx.doi.org/10.1186/1745-6215-11-32

Tran TD, Tran T, Fisher J 2013 Validation of the depression anxiety stress scales (DASS) 21 as a screening instrument for depression and anxiety in a rural community-based cohort of northern Vietnamese women. BMC Psychiatry 13. Available from: http://dx.doi.org/10.1186/1471-244x-13-24

Kao C-W, Chen T-Y, Cheng S-M, Lin W-S, Friedmann E, Thomas SA 2013 Gender differences in the predictors of depression among patients with heart failure European Journal of Cardiovascular Nursing 13 320-8. Available from:

http://dx.doi.org/10.1177/1474515113496 $\underline{493}$

Gottlieb SS, Khatta M, Friedmann E, Einbinder L, Katzen S, Baker B, et al. 2004 The influence of age, gender, and race on the prevalence of depression in heart failure patients ACC Current Journal Review 13 36. Available from: http://dx.doi.org/10.1016/j.accreview.2004. 07.048

Gaviţa OA, David D, Bujoreanu S, Tiba A, Ionuţiu DR 2012 The efficacy of a short cognitivebehavioral parent program in the treatment of externalizing behavior disorders in Romanian foster care children: Building parental 
emotion-regulation through unconditional self- and child-acceptance strategies Children and Youth Services Review 34 1290-7. Available from: http://dx.doi.org/10.1016/j.childyouth.2012. $\underline{03.001}$

Guallar-Castillón P, del Mar Magariños-Losada M, Montoto-Otero C, Tabuenca AI, RodríguezPascual C, Olcoz-Chiva M, et al. 2006 Prevalence of depression and associated medical and psychosocial factors in elderly hospitalized patients with heart failure in spain. Revista Española de Cardiología 59 770-8. Available from: http://dx.doi.org/10.1016/s1885$\underline{5857(07) 60042-5}$

Lefteriotis C 2013 Depression in Heart Failure patients Heal Sci J 7 349-55
Sheu S, Irvin BL, Lin H-S, Mar C-L 2003 Effects of Progressive Muscle Relaxation on Blood Pressure and Psychosocial Status for Clients with Essential Hypertension in Taiwan Holistic Nursing Practice 17 41-7. Available from: http://dx.doi.org/10.1097/00004650$\underline{\text { 200301000-00009 }}$

Valsaraj BP, Bhat SM, Latha KS 2016 Cognitive behavior therapy for anxiety and depression among people undergoing haemodialysis: a randomized control trial Journal of Clinical And Diagnostic Research 10 VC06-10. Available from: http://dx.doi.org/10.7860/jcdr/2016/18959 .8383 